\title{
Growth and Essential Fatty Acid Levels of Plasma and Liver of Suckling Rats from Mothers Fed on Fat-Free or Various Fat Diets
}

\author{
Nobuko Iritani,* Yohko Matsumura, and Hitomi FukUda \\ Tezukayama Gakuin College, Sakai 590-01, Japan
}

(Received December 3, 1992)

\begin{abstract}
Summary The milk fatty acid compositions of mothers fed on a fatfree or various fat diets, and the effects on growth and fatty acid compositions of their pups were studied. Even the milk of essential fatty acid-deficient mothers fed on a fat-free or hydrogenated fat diet contained about 3 and $1.7 \%, n-6$ and $n-3$ fatty acids, respectively. In the plasma of the suckling pups, however, the proportions of $n-6$ and $n-3$ fatty acids rapidly increased to about 20 and 3-5\%, respectively, at 1 week after birth. In particular, the PUFAs markedly increased in the liver PC and $\mathrm{PE}$, and the high levels were maintained until weaning. Although the PUFA compositions of suckling pups were influenced with those of maternal diet, small amounts of $n-6$ and $n-3$ fatty acids were usually maintained in the plasma and liver. After weaning to the same diets (without PUFAs) as the mothers, however, the $n-3$ and $n-6$ fatty acids rapidly decreased and endogenous $n-9$ eicosatrienoic acid appeared. On the other hand, the growth during suckling was not significantly different among the litters of mothers fed on diets with or without $n-3$ or $n-6$ fatty acids. After the weaning, however, the growth was improved in the following order: corn oil, perilla oil $>$ fish oil $>$ fat-free, hydrogenated fat diet group. $n-3$ fatty acids appeared to be used partially as substitutes for $n-6$. However, the essentiality was not clear, as the $n-3$ fatty acids always coexisted with the $n-6$. Thus, it appeared that small amounts of $n-3$ and $n-6$ fatty acids in milk were supplied to the suckling animals regardless of maternal diet and supported growth.
\end{abstract}

Key Words $n-3$ and $n-6$ fatty acids, suckling, milk, plasma, liver phospholipids, fat-free diet: (rat)

Linoleic acid, arachidonic acid, and $n-3$ linolenic acid have long been considered as essential fatty acids, particularly in developing period $(1-8)$. The apparent

* To whom all correspondence should be addressed.

Abbreviations: PUFA, polyunsaturated fatty acid; PC, phosphatidylcholine; PE, phosphatidylethanolamine. 
deficiency symptoms, such as dermatitis, poor growth, and reproduction failure (1), have been long well-known. As all of these symptoms were completely corrected by $n-6$ fatty acids, the essentiality of $n-3$ fatty acids is less apparent. However, recent studies have indicated that fish oil may be useful for reducing the risk of coronary heart disease and atherosclerosis (9-11), for treating inflammatory diseases $(12,13)$, and for brain development (14-17). Also, the specific role of $n$ 3 fatty acids in the functions of the retina and nervous system has been defined (16, 17).

As to growth, Greenberg et al. (7) reported that $n-3$ linolenic acid supported growth, while Tinoco et al. (8) found that linolenic acid did not appear to be essential for growth. On the other hand, Galli (14) reported that arachidonic acid level in milk phospholipids was not decreased by essential fatty acid deficiency of the maternal diet. The suckling rats may obtain enough essential fatty acids to grow even from mothers fed on diets without PUFAs. Thus, in the present experiment, we have tried to make clear the supply of $n-3$ or $n-6$ fatty acids to suckling pups from essential fatty acid deficient mothers and also the essentiality of $n-3$ fatty acids on growth. For the comparison, the fatty acid compositions of milk of mothers fed on various kinds of fat diets and the effects on the fatty acid compositions of plasma and liver of the suckling pups have been also studied.

\section{MATERIALS AND METHODS}

Animals. Pregnant Wistar rats (Japan SLC) were fed a fat-free or 5\% fat (corn oil, fish oil from pollack, perilla oil, or hydrogenated beef tallow) diet from the 10-14th day of gestation through the experimental period. The fat-free diet contained $67.9 \%$ sucrose, $18 \%$ casein, $9.5 \%$ cellulose, $4 \%$ salt mixture $(18), 0.1 \%$ choline chloride, and vitamins (18). The amount of $5 \%$ sucrose was substituted by fat in the diet containing 5\% fat. The fatty acid compositions of fats used in the diets are shown in Table 1. Rats were kept under an automatic lighting schedule from $0800 \mathrm{~h}$ to $2000 \mathrm{~h}$ at $24^{\circ} \mathrm{C}$. Both male and female pups were killed at various ages up to the age of 2 weeks, and only males were killed in experiments with rats older than 2 weeks. Pups were removed from mothers at the age of 3 weeks, and

Table 1. Compositions of fatty acids in dietary fat.

\begin{tabular}{|c|c|c|c|c|c|c|c|c|}
\hline Dietary fat & $16: 0$ & $16: 1$ & $18: 0$ & $18: 1^{1}$ & $\begin{array}{c}18: 2 \\
n-6\end{array}$ & $\begin{array}{c}18: 3 \\
n-3\end{array}$ & $\begin{array}{c}20: 5 \\
n-3\end{array}$ & $\begin{array}{c}22: 6 \\
n-3\end{array}$ \\
\hline & \multicolumn{8}{|c|}{$\%$ of fatty acids } \\
\hline Corn oil & 10.4 & & 2.50 & 35.7 & 50.2 & & & \\
\hline Fish oil ${ }^{2}$ & 19.7 & 11.5 & 4.54 & 15.7 & 1.40 & & 34.8 & 8.68 \\
\hline Perilla oil & 7.43 & & 2.56 & 17.2 & 12.9 & 60.0 & & \\
\hline Hydrogenated $\mathrm{fat}^{3}$ & 29.8 & & 47.8 & 20.2 & & & & \\
\hline
\end{tabular}


fed the same diet as the mothers after weaning. The animals, at fetal days 17-19, and at birth, 1, 2, 3, 4, 5, and 6 weeks, were killed. An aliquot of each liver was quickly removed and kept at $-20^{\circ} \mathrm{C}$.

Before milking, dams were injected intraperitoneally with 4 IU oxytocin (Sigma Chemical Co.) and then were anesthetized $10 \mathrm{~min}$ later with diethylether. Milk was obtained in capillary tubes attached to a vacuum pump.

Lipid extraction, fractionation, and fatty acid analysis. Total lipids of milk, plasma, and liver were extracted according to the method of Folch et al. (19). Liver PC and PE were separated by thin-layer chromatography with a solvent of chloroform/methanol/water $(65: 25: 4$, by volume). The silica gel zones corresponding to PC and PE were extracted and saponified. The fatty acids were methylated with $m$-trifluoromethylphenyltrimethyl ammonium hydroxide and applied onto a Shimadzu 9A gas chromatograph with a capillary column of CBP-M 20-025 (Shimadzu), poly (ethylene glycol) coated in a tube $0.25 \mathrm{~mm} \times 25 \mathrm{~m}$. The oven temperature was increased from 60 to $230^{\circ} \mathrm{C}$ at $6^{\circ} \mathrm{C} / \mathrm{min}$ and finally maintained at $230^{\circ} \mathrm{C}$ for $20 \mathrm{~min}$. The carrier gas was nitrogen. Other details were reported previously (20).

Statistical analysis. Statistical evaluation of the results was carried out by Student's $t$-test or by one-way analysis of variance (21).

\section{RESULTS AND DISCUSSION}

\section{Growth curves}

The body weight gains were not significantly different among the suckling rats of mothers fed on a fat-free, hydrogenated fat, corn oil, perilla oil, or fish oil diet (Fig. 1). After weaning to the same diets as the mothers, however, the weight gain was less in the fish oil than in the corn oil or perilla oil group, and further less in the fat-free or hydrogenated fat than in the fish oil group. It appeared that the $n-6$ fatty acids had an important role for growth and the $n-3$ fatty acids could be partially used as substitutes for the $n-6$. Greenberg et al. (7) reported that $n-3$ linolenic acid supported growth, while Tinoco et al. (8) found that linolenic acid did not appear to be essential for growth. From the present results, it is suggested that $n-3$ fatty acids partially supported the pups' growth, while the essentiality of $n-3$ fatty acids for growth was not clear. On the other hand, as the growth during suckling was not significantly different among the litters of mothers fed on diets with or without PUFAs, the suckling pups appeared to get essential fatty acids from mother's milk. Therefore, the fatty acid compositions of milk of the mothers and those of plasma and liver of the pups were examined.

\section{Milk fatty acid composition}

The typical fatty acid compositions of milk at 2 weeks after parturition are shown in Table 2. The plasma fatty acid compositions of the mothers are also shown. n-9 eicosatrienoic acid appeared in the plasma of the fat-free and the 


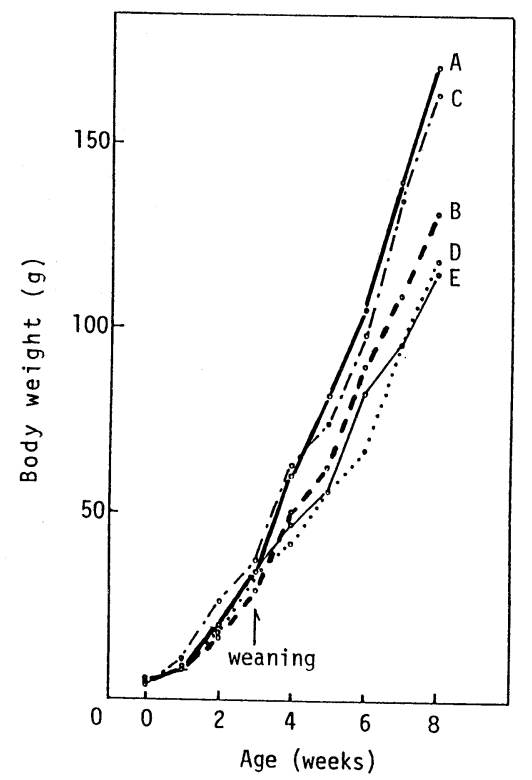

Fig. 1. Effects of dietary fat of mothers on pups' growth during development. Pregnant rats were fed 5\% corn oil (A), fish oil (B), perilla oil (C), hydrogenated fat (D), or a fat-free diet (E) from the 10-14th day of gestation. After suckling for 3 weeks, the pups were weaned to the same diet as the mothers. The arrow shows the weaning. Mean values of body weight for pups (31-70 pups) of 4-12 mother rats are shown. The standard deviations are omitted and were usually $4-16 \%$ of the means.

hydrogenated fat groups, and the plasma $n-9 / n-6$ ratios were over 0.2 . Therefore, the mothers were considered to be essential fatty acid-deficient (22). The mothers were fed the fat-free, corn oil, perilla oil, fish oil, or hydrogenated fat diet from the 10-14th day of gestation (for more than 3 weeks). Although $n-9$ eicosatrienoic acid was about $4 \%$ in the plasma, it was less than $1 \%$ in the milk. The proportion of linoleic acid in the milk of mothers fed on the corn oil diet was $18 \%$, but that of arachidonic acid, only $2 \%$. In the milk of fish oil group, the proportion of $n-3$ fatty acids was only about $7 \%$ even on feeding plenty of the $n-3$ fatty acids, and linoleic acid was about $3 \%$. In the milk of perilla oil group, the composition of $n-3$ linolenic acid was $9 \%$ (although perilla oil contained $60 \%$ of $n-3$ linolenic acid), but $n-3$ eicosapentaenoic acid plus docosahexaenoic acid, only 2-3\%. Particularly PUFAs with more than three double bonds were only slightly contained in the milk, as compared to the plasma. It was remarkable that, even in the milk fatty acids of essential fatty acid-deficient animals fed on the fat-free or hydrogenated fat diet for more than 3 weeks, $2-4 \%$ of linoleic acid, $0.6 \%$ of arachidonic acid, and about $2 \%$ of $n-3$ fatty acids were found. It was reported that arachidonic acid level in milk phospholipids was not modified by the fatty acid composition of the maternal diet 
Table 2. Compositions of fatty acids in total lipids of milk and plasma of mothers fed on various kinds of fat diet.

\begin{tabular}{|c|c|c|c|c|c|c|c|c|c|c|}
\hline Dietary fat & $16: 0$ & $16: 1$ & $18: 0$ & $18: 1$ & $\begin{array}{c}18: 2 \\
n-6\end{array}$ & $\begin{array}{c}18: 3 \\
n-3\end{array}$ & $\begin{array}{c}20: 3 \\
n-9\end{array}$ & $\begin{array}{c}20: 4 \\
n-6\end{array}$ & $\begin{array}{c}20: 5 \\
n-3\end{array}$ & $\begin{array}{c}22: 6 \\
n-3\end{array}$ \\
\hline & \multicolumn{10}{|c|}{$\%$ of milk fatty acids ${ }^{1}$} \\
\hline Corn oil & $22.0^{\mathrm{a}}$ & $2.97^{\mathrm{a}}$ & $3.94^{\mathrm{a}}$ & $25.4^{\mathrm{a}}$ & $18.2^{\mathrm{a}}$ & $n d^{2}$ & nd & $1.77^{\mathrm{a}}$ & $1.14^{\mathrm{a}}$ & $1.17^{\mathrm{a}}$ \\
\hline Perilla oil & $23.6^{\mathrm{a}}$ & $2.36^{\mathrm{a}}$ & $3.93^{\mathrm{a}}$ & $18.2^{\mathrm{b}}$ & $6.45^{\mathrm{b}}$ & 8.83 & nd & $0.44^{\mathrm{b}}$ & $1.33^{\mathrm{a}}$ & $1.29^{\mathrm{a}}$ \\
\hline Fish oil & $25.4^{\mathrm{a}}$ & $4.85^{\mathrm{b}}$ & $4.16^{\mathrm{a}}$ & $22.6^{\mathrm{a}}$ & $3.41^{\mathrm{c}}$ & nd & nd & $0.68^{\mathrm{b}}$ & $3.55^{\mathrm{b}}$ & $3.15^{\mathrm{b}}$ \\
\hline Hydrogenated fat & $27.9^{\mathrm{b}}$ & $5.30^{\mathrm{b}}$ & $7.82^{\mathrm{b}}$ & $21.2^{\mathrm{ab}}$ & $2.41^{\mathrm{c}}$ & nd & 0.84 & $0.57^{\mathrm{b}}$ & $0.80^{\mathrm{a}}$ & $0.81^{\mathrm{c}}$ \\
\hline \multirow[t]{2}{*}{ Fat-free } & $28.7^{\mathrm{b}}$ & $4.70^{b}$ & $3.47^{\mathrm{a}}$ & $26.5^{\mathrm{a}}$ & $3.88^{\mathrm{c}}$ & nd & 0.96 & $0.62^{\mathrm{b}}$ & $0.84^{\mathrm{a}}$ & $0.97^{\mathrm{ac}}$ \\
\hline & \multicolumn{10}{|c|}{$\%$ of plasma fatty acids } \\
\hline Corn oil & $25.9^{\mathrm{a}}$ & $3.14^{\mathrm{a}}$ & $14.8^{\mathrm{ac}}$ & $18.9^{\mathrm{a}}$ & $22.3^{\mathrm{a}}$ & nd & nd & $13.3^{\mathrm{a}}$ & nd & nd \\
\hline Perilla oil & $21.5^{\mathrm{b}}$ & $2.15^{\mathrm{b}}$ & $10.0^{\mathrm{b}}$ & $19.3^{\mathrm{a}}$ & $12.9^{\mathrm{b}}$ & 8.23 & nd & $7.45^{\mathrm{b}}$ & $7.92^{\mathrm{a}}$ & $5.90^{\mathrm{a}}$ \\
\hline Fish oil & $21.0^{\mathrm{b}}$ & $4.92^{\mathrm{c}}$ & $12.3^{\mathrm{c}}$ & $26.4^{\mathrm{b}}$ & $5.78^{\mathrm{c}}$ & nd & nd & $6.68^{b}$ & $8.84^{\mathrm{a}}$ & $10.5^{b}$ \\
\hline Hydrogenated fat & $16.4^{c}$ & $7.06^{\mathrm{d}}$ & $16.3^{\mathrm{d}}$ & $25.2^{\mathrm{b}}$ & $6.80^{\mathrm{c}}$ & nd & 4.08 & $16.7^{\mathrm{c}}$ & $0.34^{\mathrm{b}}$ & $0.64^{\mathrm{c}}$ \\
\hline Fat-free & $17.8^{\mathrm{c}}$ & $6.38^{\mathrm{d}}$ & $12.6^{\mathrm{c}}$ & $27.6^{\mathrm{b}}$ & $6.50^{\mathrm{c}}$ & nd & 3.69 & $17.2^{\mathrm{c}}$ & $1.05^{\mathrm{c}}$ & $1.21^{\mathrm{d}}$ \\
\hline
\end{tabular}

Pregnant rats were fed on a fat-free or $5 \%$ fat diet from the 10-14th day of gestation. The fatty acid compositions of milk were not significantly different during lactation. Therefore, the fatty acid compositions 2 weeks after parturition are shown. ${ }^{1}$ In the milk of the dietary groups, the composition of octanoic acid (8:0) was 1.00-1.66\%; decanoic acid (10:0), 6.10-7.95\%; lauric acid (12:0), 6.97-9.61\%; myristic acid (14:0), 6.99-12.0\%. The fatty acid compositions of plasma 2 weeks after parturition are shown. Statistical evaluation of the result was carried out by one-way analysis of variance. The standard deviations are omitted but were mostly $8-15 \%$. Means with different superscript letters are significantly different at $p<0.05$ at least $(n=3-5) .{ }^{2}$ nd, not detected.

(14). We have also found that a small amount of arachidonic acid is contained in the milk of the fat-free, hydrogenated fat, fish oil, and perilla oil groups but a little more is found in the milk of corn oil group. Even in the milk of the corn oil group, the amount of arachidonic acid was not much. In addition, small amounts of eicosapentaenoic acid and docosahexaenoic acid were also contained in the milk, regardless of the fatty acid compositions of maternal diet. It is suggested that the pups obtained the PUFAs from milk and preserved them, and consequently grew normally. The small amounts of the PUFAs appeared to be able to maintain growth.

\section{Plasma fatty acid composition of suckling rats}

Even in the plasma of suckling rats of mothers fed on the fat-free, hydrogenated fat or fish oil groups, the proportion of linoleic acid increased rapidly after birth and reached the maximal levels of about $10 \%$ in 1 week, although that of fetus was 3-4\% (Fig. 2). Then the proportion of linoleic acid gradually decreased after the weaning to the diet containing no linoleic acid and reached $2-4 \%$ at 4 weeks. The proportions of arachidonic acid were the maximum levels of $14-17 \%$ at 1 week 


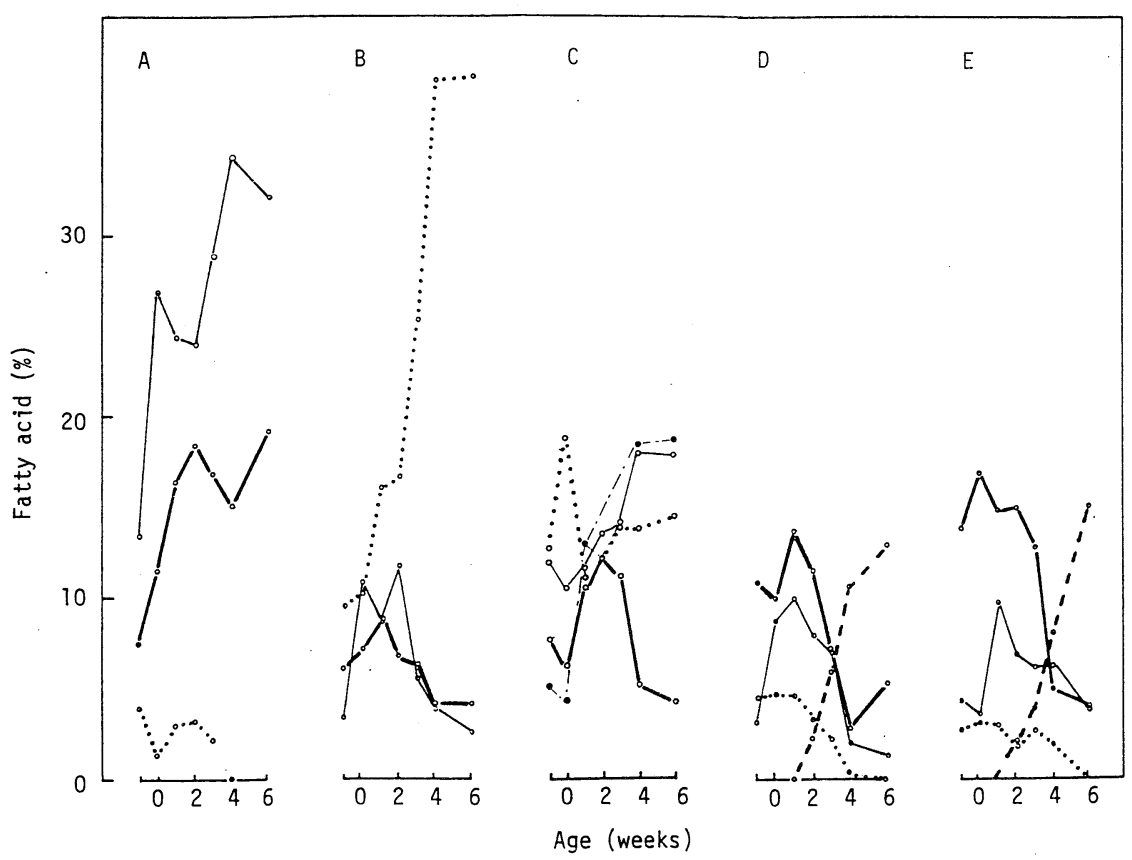

Fig. 2. Effects of dietary fat of mothers on PUFA composition in total lipids of plasma of pups during development. Pregnant rats were fed 5\% corn oil (A), fish oil (B), perilla oil (C), hydrogenated fat (D), or a fat-free diet (E) from the 10-14th day of gestation through the experiment. After suckling for 3 weeks, the pups were weaned to the same diet as the mothers. Mean values of the proportions of linoleic acid (-), arachidonic acid (-), $18: 3 n-3$ $(---), 20: 5$ plus $22: 6 n-3(\cdots \cdots)$, and $20: 3 n-9(-\cdots)$ are shown. Five samples of plasma were pooled and analyzed. The values before birth show data at fetal days 17-19. The standard deviations are omitted but were usually 5$15 \%$ of mean values $(n=3-5$ litters $)$.

after birth, kept the high level during suckling, then gradually decreased after weaning and reached only $3-5 \%$ at 4 weeks after birth (1 week after weaning). Even in the plasma of the suckling animals of mothers fed no $n-3$ fatty acids, the $n$ 3 fatty acids also were $3-5 \%$. When $n-3$ or $n-6$ fatty acids decreased to less than $3 \%$ at 4 weeks old after weaning to the fat-free or hydrogenated fat diet, $n-9$ eicosatrienoic acid appeared and then increased to about 15\%. Thus, in the plasma of litters of mothers fed on the corn oil or fish oil diet, $n-6$ or $n-3$ fatty acids, respectively, increased rapidly and markedly after birth. Moreover, even in the plasma of litters of the groups fed no PUFAs, the fatty acids increased somewhat after birth. 


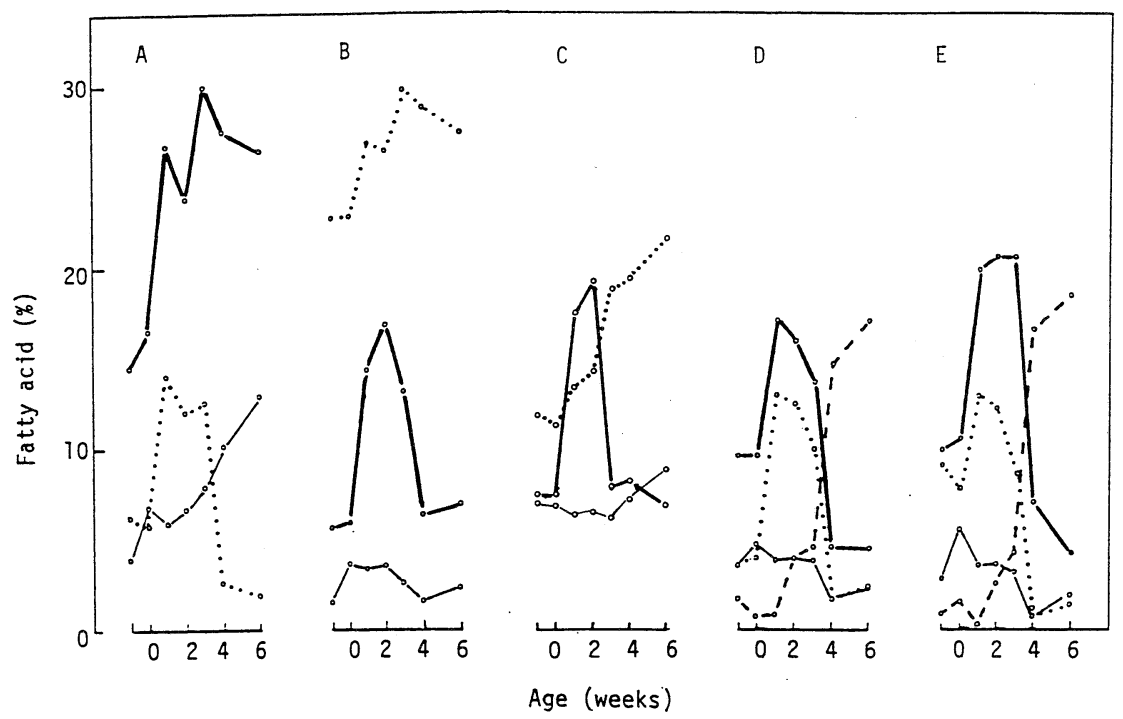

Fig. 3. Effects of dietary fat of mothers on PUFA composition of liver PC of pups during development. Pregnant rats were fed 5\% corn oil (A), fish oil (B), perilla oil (C), hydrogenated fat (D), or fat-free diet (E) from the 10-14th day of gestation through the experiment. After suckling for 3 weeks, the pups were weaned to the same diet as the mothers. Mean values of the proportions of linoleic acid (-), arachidonic acid (-), 20:5 plus $22: 6 n-3(\cdots \cdots)$, and $20: 3 n-9(---)$ are shown. The values before birth show data at fetal days 1719. Five samples of livers were pooled and analyzed. The standard deviations are omitted but were usually $5-15 \%$ of mean values $(n=3-5$ litters $)$.

\section{Liver phospholipid fatty acid composition of suckling rats}

The changes in $n-3$ and $n-6$ fatty acids of liver phospholipids after birth were similar to those of plasma, but the changes were more remarkable in the liver phospholipids. In the livers of suckling rats of mothers even fed on the fat-free or hydrogenated fat diet, the proportion of arachidonic acid was 15-20\% in PC and PE. The proportion of $n-3$ fatty acids rapidly and greatly increased after birth, to about $13 \%$ in PC and $20-25 \%$ in PE of the livers (Figs. 3 and 4). Although the proportions of $n-3$ fatty acids were low in the fetus of mothers fed on diets without PUFAs, the proportions rapidly increased in hepatic PC and PE after birth in transition from fetus to suckling. In the liver PC and PE of suckling rats of the corn oil group, both arachidonic acid and $n-3$ fatty acids rapidly increased after birth and were kept at high levels during suckling, but the $n$ - 3 fatty acids rapidly decreased after weaning to the corn oil diet (the same as the mothers). After weaning to the fish oil diet (the same diet as the mothers), the $n-6$ fatty acids rapidly decreased. In suckling rats of mothers fed on the fat-free or hydrogenated fat diet, the ratios of $n-3 / n-6$ fatty acids in PC and PE of the liver was about $1 / 2$ and $1 / 1.3$, 


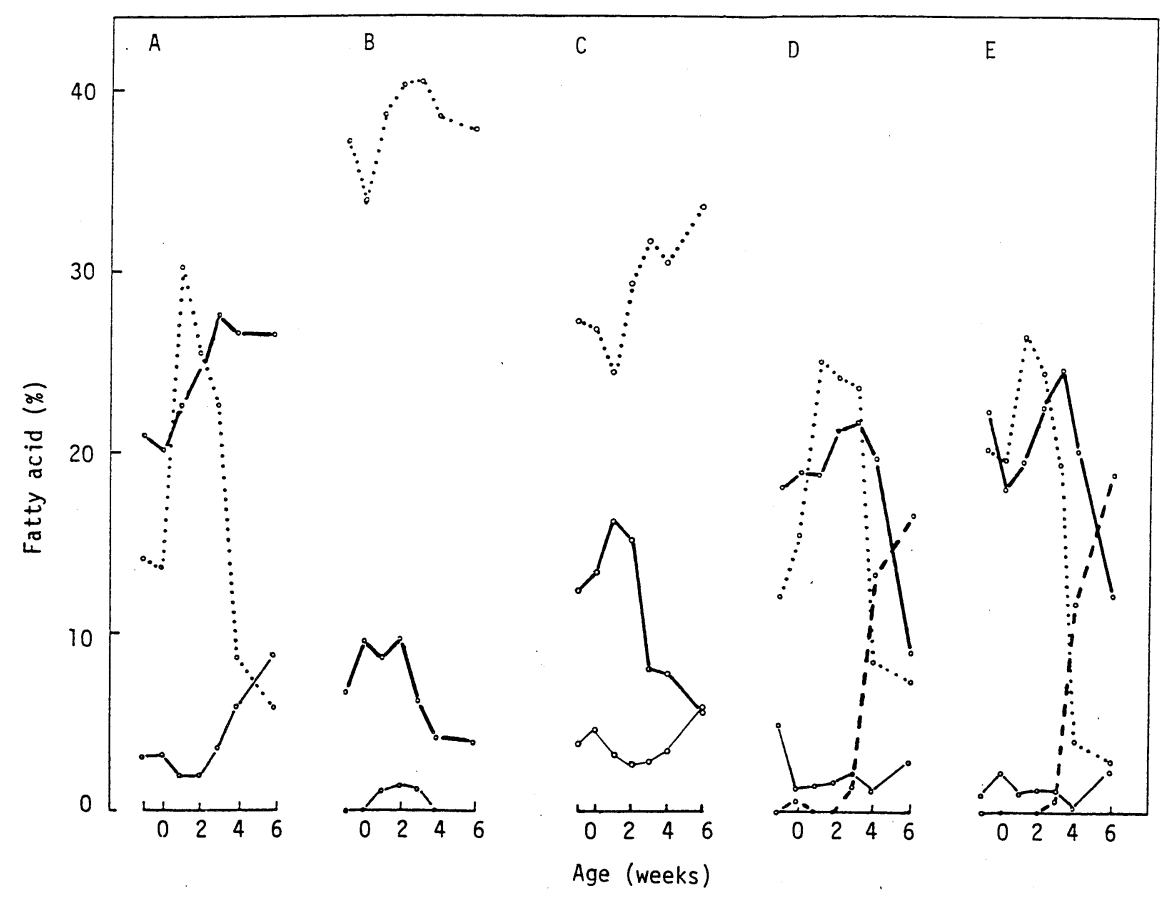

Fig. 4. Effects of dietary fat of mothers on PUFA composition of liver PE of pups during development. Pregnant rats were fed 5\% corn oil (A), fish oil (B), perilla oil (C), hydrogenated fat (D), or fat-free diet (E) from the 10-14th day of gestation through the experiment. After suckling for 3 weeks, the pups were weaned to the same diet as the mothers. Mean values of the proportions of linoleic acid ( - ), arachidonic acid (-), 20:5 plus $22: 6 n-3(\cdots \cdots)$, and $20: 3 n-9(--)$ are shown. The values before birth show data at fetal days 1719. Five samples of livers were pooled and analyzed. The standard deviations are omitted but were usually $5-15 \%$ of mean values $(n=3-5$ litters $)$.

respectively, while the ratio in plasma was $1 / 5-1 / 7$. The ratio in milk was $1 / 2-1 / 3$. These ratios may be physiologically significant, as the mothers were in a critical situation of being fed no PUFAs for a long time but the pups grew normally. Many scientists have studied the ratios of $n-3 / n-6$ in the cellular membranes and also the desirable ratios in dietary intake, with conflicting results (17).

The hepatic levels of phospholipids were low at birth, but quickly increased and reached the weaned levels at 1 week. The phospholipid levels did not subsequently alter (23). Therefore, the concentrations of each fatty acid of phospholipids in the liver after 1 week old would be parallel to the percentages of fatty acid compositions.

After weaning to the fat-free or hydrogenated fat diet (the same diet as the mothers), both the $n-6$ and $n-3$ fatty acids in plasma and liver rapidly decreased. 
Instead, the n-9 eicosatrienoic acid appeared in PC and PE. Therefore, it is suggested that, as these essential fatty acids were barely supplied to the suckling pups, even from the mothers fed on the fat-free diet, the weight gains were similar among the litters of mothers fed on the fat-free, hydrogenated fat, fish oil, and corn oil diet. After weaning to the same diet as the mother, however, the weight gain was more in the corn oil group than in the fat-free or hydrogenated fat group.

It was reported that the proportions of $n-3$ and $n-6$ PUFAs in the suckling tissues were positively related to the amount of the corresponding fatty acid in the maternal diet $(24,25)$. The present results were also similar. In addition, however, it has been found that $n-3$ as well as $n-6$ fatty acids are supplied to the suckling rat even from the fatty acid-deficient mother, regardless of the maternal diet, and preserved by the suckling animals. However, the essentiality of $n-3$ fatty acids has not been made clear, as $n-3$ fatty acids always coexisted with $n-6$. As long as suckling pups are taking mother milk, essential fatty acids appeared to be barely supplied.

\section{REFERENCES}

1) Holman, R. T. (1968): Essential fatty acid deficiency, in Progress in the Chemistry of Fats and Other Lipids, Vol. 9, Pergamon Press, Oxford, pp. 275-348.

2) Pudelkewicz, C., Seufert, J., and Holman, R. T. (1968): Requirements of the female rat for linoleic and linolenic acids. J. Nutr., 94, 138-146.

3) Williams, M. A., Tamai, K. T., Hincenbergs, I., and McIntosh, D. J. (1972): Hydrogenated coconut oil and tissue fatty acids in EFA-depleted and EFAsupplemented rats. J. Nutr., 102, 847-856.

4) Lamptey, M. S., and Walker, B. L. (1976): A possible essential role for dietary linolenic acid in the development of the young rat. J. Nutr., 106, 86-93.

5) Aaes-Joergensen, E., and Hoelmer, G. (1969): Essential fatty acid-deficient rats. 1. Growth and testes development. Lipids, 4, 501-506.

6) Farrell, P. M., Gutcher, G. R., Palta, M., and DeMets, D. (1988): Essential fatty acid deficiency in premature infants. Am. J. Clin. Nutr., 48, 220-229.

7) Greenberg, S. M., Calbert, C. E., Savage, E. E., and Deuel, H. J., Jr. (1950): The effect of fat level of the diet on general nutrition. (VI) The interrelation of linoleate and linolenate in supplying the essential fatty acid requirement in the rat. J. Nutr., 41, 473-486.

8) Tinoco, R. J., Williams, M. A., Hincenberg, I., and Lyman, R. L. (1971): Evidence for nonessentiality of linoleic acid in the diet of the rat. J. Nutr., 101, 937-945.

9) Dyerberg, J., Bang, H. O., and Hjorne, N. (1975): Fatty acid composition of the plasma lipids in Greenland Eskimos. Am. J. Clin. Nutr., 28, 958-966.

10) Phillipson, B. E., Rothrock, D. W., Harris, W. S., and Illingworth, D. R. (1985): Reduction of plasma lipids, lipoproteins, and apoproteins by dietary fish oils in patients with hyperglyceridemia. N. Engl. J. Med., 312, 1210-1216.

11) Leaf, A., and Weber, P. C. (1988): Cardiovascular effects of $n-3$ fatty acids. N. Engl. J. Med., 318, 549-557.

12) Kremer, J. M., Michalek, A. V., Lininge, L., Huyck, C., Bigauoette, J., Timchalk, M. 
A., Rynes, R. I., and Zieminski, J. (1985): Effects of manipulation of dietary fatty acids on clinical manifestations of rheumatoid arthritis. Lancet, 1, 184-187.

13) Lee, T. H., Hoover, R. L., Williams, J. D., Sperling, R. I., Ravelese, J., Spur, B. W., Robinson, D. R., Corey, E. J., Lewis, A. A., and Austen, K. F. (1985): Effect of dietary enrichment with eicosapentaenoic and docosahexaenoic acids on in vitro neutrophil and monocyte leukotrine generation and neutrophil function. N. Engl. J. Med., 312, 1217-1224.

14) Galli, C. (1973): Dietary lipids and brain development, in Dietary Lipids and Postnatal Development, ed. by Galli, C., Jacini, G., and Pecile, A., Raven, New York, pp. 191-202.

15) Crawford, M. A., Hassam, A. G., and Stevens, P. A. (1981): Essential fatty acid requirements in pregnancy and lactation with special reference to brain development. Prog. Lipid Res., 20, 31-40.

16) Neuringer, M., Anderson, G. J., and Connor, W. E. (1988): The essentiality of $n-3$ fatty acids for the development and function of the retina and brain. Annu. Rev. Nutr., 8, 517-541.

17) Simopoulos, A. P. (1989): Summary of the NATO advanced research workshop on dietary 3 and 6 fatty acids: Biological effects and nutritional essentiality. J. Nutr., 119, 521-528.

18) Iritani, N., Fukuda, E., and Inoguchi, K. (1979): Effect of feeding the shell fish on lipid metabolism in the rat. Atherosclerosis, 34, 41-47.

19) Folch, J., Less, N., and Sloane-Stanley, G. H. (1957): A simple method for the isolation and purification of total lipids from animal tissues. J. Biol. Chem., 226, 497509.

20) Iritani, N., Fukuda, H., and Matsumura, Y. (1988): Effects of corn oil- and fish oil-supplemented diets on phospholipid fatty acid composition of rat liver nuclei. Biochim. Biophys. Acta, 963, 224-230.

21) Snedecor, G. W., and Cochram, W. G. (1967): Statistical Methods, Iowa State University Press, Ames, IA, pp. 285-338.

22) Holman, R. T. (1960): The ratio of trienoic : tetraenoic acids in tissue lipids as a measure of essential fatty acid requirement. J. Nutr., 70, 405-411.

23) Iritani, N., Fukuda, H., and Matsumura, Y. (1993): Lipogenic enzyme gene expression in rat liver during development after birth. J. Biochem., 113, 519-525.

24) Yeh, Y.-Y., Winters, B. L., and Yeh, S.-M. (1990): Enrichment of $n-3$ fatty acids of suckling rats by maternal dietary menhaden oil. J. Nutr., 120, 436-443.

25) Ferris, A. M., and Jensen, R. G. (1984): Lipids in human milk: A review. 1. Sampling, determination content. J. Pediatr. Gastroenterol. Nutr., 3, 108-122. 